\title{
L-ARGININE, A NITRIC OXIDE PRECURSOR, ATTENUATES ISCHEMIA-REPERFUSION INJURY BY INHIBITING INOSITOL-1,4,5-TRIPHOSPHATE
}

Tomohiro Mizuno, MD

Masazumi Watanabe, MD

Tohru Sakamoto, MD

Makoto Sunamori, MD
Objective: We evaluated the effect of pretreatment with nitric oxide precursor before ischemia on recovery with reperfusion in rat hearts. Methods: Isolated rat hearts were perfused with Krebs-Henseleit buffer without (C group) or with $3 \mathrm{mmol} / \mathrm{L}$ L-arginine (A group) before 30 minutes of ischemia. The left ventricular function, including heart rate, developed pressure, maximal $\mathrm{dp} / \mathrm{dt}$, and coronary flow, were measured before pretreatment and after 10 and 30 minutes of reperfusion. Cyclic guanosine monophosphate (by radioimmunoassay), calcium (by absorption spectrophotometry), and inositol 1,4,5-triphosphate synthesized from tritiated myo-inositol (by ion-exchange chromatography preceding counting) were measured at the same times and immediately after ischemia. Results: Recovery of ventricular function was significantly greater in the A group than in the $\mathrm{C}$ group. Pretreatment increased postischemic cyclic guanosine monophosphate content compared with the preischemic level (from $1.06 \pm$ 0.12 to $1.94 \pm 0.09 \mathrm{pmol} / \mathrm{mg}$ protein, $p<0.05)$. No change in cyclic guanosine monophosphate was evident in the $\mathrm{C}$ group. In the $\mathrm{C}$ group, inositol triphosphate content increased after 10 minutes of reperfusion beyond the preischemic level (from $0.53 \pm 0.023$ to $1.15 \pm 0.045 \mathrm{cpm} \times$ $10^{-3} / \mathrm{gm}, p<0.05$ ) as did calcium at 30 minutes (from $4.12 \pm 0.164$ to $6.86 \pm$ $0.544 \mathrm{mmol} / \mathrm{gm}$ dry weight). In the A group, both of these increases were significantly attenuated. Conclusion: These data suggest that L-arginine pretreatment may reduce calcium overload by increasing cyclic guanosine monophosphate production, which in turn downregulates inositol triphosphate synthesis during reperfusion. (J Thorac Cardiovasc Surg 1998;115: 931-6)
$\mathrm{N}$ itric oxide (NO), an endothelially derived, smooth muscle-relaxing factor, is well known as a physiologically important vasodilator. Recent papers have suggested that NO also is a regulator of cell metabolism, which can reduce adenosine triphosphate (ATP) by inhibiting glyceraldehyde-3phosphate dehydrogenase (GAPDH) and mito-

From the Department of Thoracic and Cardiovascular Surgery, School of Medicine, Tokyo Medical and Dental University, Tokyo, Japan.

Received for publication May 9, 1997; revisions requested August 12, 1997; revisions received Sept. 11, 1997; accepted for publication Sept. 11, 1997.

Address for reprints: Masazumi Watanabe, MD, Department of Thoracic and Cardiovascular Surgery, School of Medicine, Tokyo Medical and Dental University, 5-45, Yushima, 1-Chome, Bunkyo-ku, Tokyo 113, Japan.

Copyright (C) 1998 by Mosby, Inc.

$0022-5223 / 98 \$ 5.00+0 \quad \mathbf{1 2 / 1 / 8 6 1 9 3}$ chondrial function ${ }^{1}$ and cause cell injury by production of peroxynitrite. ${ }^{2,3}$

Previous studies have demonstrated that NO increases cyclic guanosine monophosphate (cGMP) in vascular smooth muscle cells by activation of soluble guanylate cyclase (sGC). ${ }^{4}$ Other investigators have reported that cGMP decreases the cytosolic $\mathrm{Ca}^{2+}$ content, or $\left[\mathrm{Ca}^{2+}\right] \mathrm{i}$ through several mechanisms, including inhibition of the phosphatidylinositol pathway, ${ }^{5,6}$ indirect inhibition of $\mathrm{Ca}^{2+}$ channels, ${ }^{7}$ and stimulation of plasma membrane $\mathrm{Ca}^{2+}$ pumps. 8,9

In addition, some studies have linked the cardioprotective effects of NO in ischemia-reperfused hearts to attenuation of neutrophil accumulation and adhesion, ${ }^{10-16}$ inhibition of superoxide anion production, ${ }^{17-19}$ and protection of coronary endothelial cell function. ${ }^{11,20}$ An NO precursor as a pretreatment or an addition to a cardioplegic solution is an appealing prospect in cardiac surgery, 


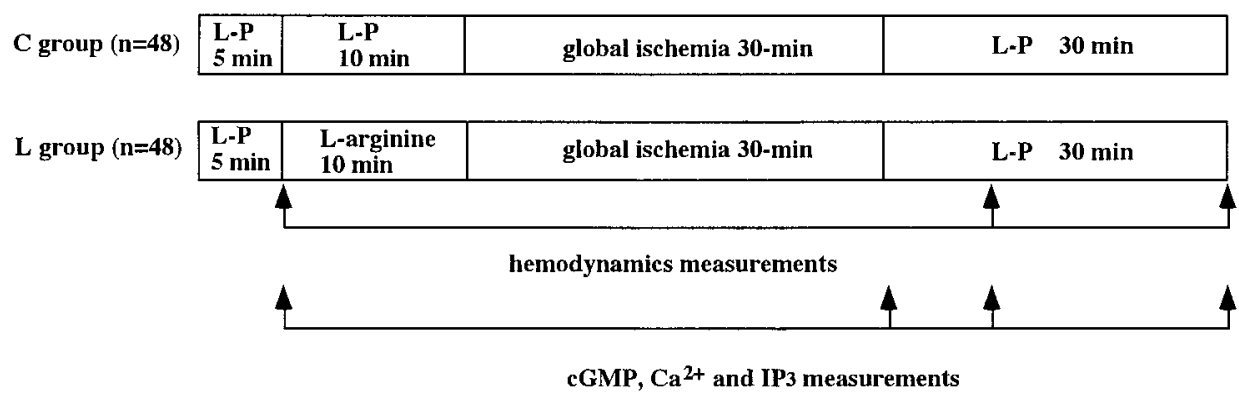

Fig. 1. Experimental protocol: A time line is given for the study as conducted in each heart. After 5 minutes of Langendorff perfusion $(L-P)$ with normal modified Krebs-Henseleit bicarbonate buffer (KHB), baseline myocardial functions were carried out. After this, L-P with drugs buffered in KHB was established for a total of 10 minutes and then the heart was replaced for 30 minutes of normothermic global ischemia and reperfused with normal KHB for 30 minutes. Biopsy specimens for cGMP and calcium were taken at the baseline point, 30 minutes after ischemia, 10 minutes after reperfusion, and 30 minutes after reperfusion. In addition, separate hearts were perfused for 45 minutes with $50 \mathrm{ml} \mathrm{KHB}$ containing $20 \mu \mathrm{Ci}$ of $\left[{ }^{3} \mathrm{H}\right]$ myo-inositol for the measurements of inositol-1,4,5-monophosphate. In the $\mathrm{C}$ group no drug was used, whereas the L group had L-arginine administered for 10 minutes before ischemia.

provided it is safe. We explored mechanisms of cardioprotection by such pretreatment in isolated rat hearts.

\section{Methods}

The investigation was performed in accordance with the guidelines in the Guide for the Care and Use of Laboratory Animals published by the U.S. National Institutes of Health (NIH publication No 85-23, revised 1985).

Experimental preparation. Male Sprague-Dawley rats (body weight 250 to $300 \mathrm{gm}$ ) were anesthetized by intraperitoneal injection of pentobarbital $(80 \mathrm{mg} / \mathrm{kg})$ and heparinized (200 units via the femoral vein). After thoracotomy, their hearts were rapidly excised and arrested in cold-modified Krebs-Henseleit bicarbonate buffer solution (mKHB buffer: $\mathrm{NaCl}, 118 \mathrm{mEq} / \mathrm{L} ; \mathrm{KCl}, 4.7 \mathrm{mEq} / \mathrm{L}$; $\mathrm{KHPO}_{4}, 1.2 \mathrm{mEq} / \mathrm{L} ; \mathrm{NaHCO}_{3}, 24 \mathrm{mEq} / \mathrm{L} ; \mathrm{MgSO}_{4}, 1.2$ $\mathrm{mEq} / \mathrm{L}$; glucose, $10 \mathrm{mEq} / \mathrm{L}$; $\mathrm{CaCl}_{2}, 1.7 \mathrm{mEq} / \mathrm{L}$; gassed with $95 \%$ oxygen and $5 \%$ carbon dioxide, $\mathrm{pH} 7.4$ ). The ascending aorta was cannulated and hearts were perfused in the nonrecirculating Langendorff mode with mKHB buffer at $37^{\circ} \mathrm{C}$ at a pressure of $100 \mathrm{~cm} \mathrm{H}_{2} \mathrm{O}$ for 10 minutes. Myocardial temperature was maintained at $37^{\circ} \mathrm{C}$ by a surrounding water jacket.

Experimental protocol. The experimental protocol is represented as a time line in Fig. 1. After an initial 10-minute perfusion, hearts were perfused another 10 minutes with mKHB buffer (C group) or with mKHB buffer containing $3 \mathrm{mmol} / \mathrm{L}$ L-arginine (A group, Sigma Chemical Co., St. Louis, Mo.). The hearts were then subjected to 30 minutes of normothermic global ischemia, after which they were perfused with $\mathrm{mKHB}$ buffer at $37^{\circ} \mathrm{C}$ for 30 minutes. Modified KHB buffer was gassed with $95 \%$ oxygen and $5 \%$ carbon dioxide during the experiments, and oxygen tension of mKHB was kept higher than 600 $\mathrm{mm} \mathrm{Hg}$ after reperfusion. Contractile functions were obtained at baseline before the first perfusion (Base) and after 10 (R10) and 30 minutes (R30) of reperfusion. Tissue samples for the measurement of cGMP, inositol phosphates, and calcium content were obtained each time from the separate rats, which were perfused and reperfused on the same protocol. Rats were randomly assigned to the treatment group and the resected tissue samples of each time. Total number of the hearts was 96 .

Myocardial contractile function. Aspects of left ventricular function evaluated included heart rate (beats/ min), maximum developed pressure (dp max, $\mathrm{mm} \mathrm{Hg}$ ), the first derivative of the left ventricular pressure (LV $\mathrm{dp} / \mathrm{dt} \max , \mathrm{mm} \mathrm{Hg} / \mathrm{sec}$ ), and coronary blood flow. Pressures were measured with a fluid-filled compliant balloon $(0.5 \mathrm{ml})$ that was connected by fluid-filled polyethylene tubing to a pressure transducer (P23ID; Gould, Inc., Cleveland, Ohio). The balloon was inserted into the left ventricle through the mitral valve. Developed pressure was measured as the difference between peak systolic pressure and end-diastolic pressure. Coronary flow $(\mathrm{ml} /$ min) was assessed by measuring the volume of coronary effluent ones ( $n=12$; six rats were used in each group. These 12 hearts were also used as the samples of intracellular $\mathrm{Ca}^{2+}$ concentration and cGMP after 30 minutes of reperfusion.)

Intracellular calcium concentration. After left ventricular function was measured and also after ischemia, transmural tissue specimens were obtained from the left ventricular wall. Myocardial calcium $(\mathrm{Ca})$ concentrations were determined using atomic absorption spectrophotometry. Approximately $0.3 \mathrm{gm}$ of myocardial tissue was homogenized with lanthanum chloride and hydrochloride solution to avoid interference by protein or anions. The supernatant obtained from homogenates centrifuged for 15 minutes at $10,000 \mathrm{rpm}$ was used for measurement of $\mathrm{Ca}^{2+}$ with the $422.7 \mathrm{~nm}$ line of a Ca hollow-cathode lamp 
Table I. Cardiac function

\begin{tabular}{|c|c|c|c|c|}
\hline Variable & & Baseline & R10 & $R 30$ \\
\hline \multirow[t]{2}{*}{ Developed pressure (mm Hg) } & $\mathrm{C}$ group & $102.5 \pm 9.5$ & $47.7 \pm 12.3^{*}$ & $57.3 \pm 12.2^{*}$ \\
\hline & A group & $103.0 \pm 8.2$ & $98.3 \pm 11.5^{*} \dagger$ & $94.8 \pm 5.3^{* \dagger}$ \\
\hline \multirow[t]{2}{*}{$\mathrm{LVdp} / \mathrm{dt} \max (\mathrm{mm} \mathrm{Hg} / \mathrm{sec})$} & C group & $1039 \pm 131$ & $418 \pm 108^{*}$ & $490 \pm 122^{*}$ \\
\hline & A group & $1101 \pm 119$ & $822 \pm 69 \dagger$ & $875 \pm 48 \dagger$ \\
\hline \multirow[t]{2}{*}{ Coronary flow (ml/min) } & C group & $15.9 \pm 1.0$ & $11.4 \pm 2.5^{*}$ & $9.0 \pm 1.9^{*}$ \\
\hline & A group & $16.7 \pm 0.9$ & $17.1 \pm 0.9 \dagger$ & $14.3 \pm 1.3 \dagger$ \\
\hline \multirow[t]{2}{*}{ Heart rate (beats/min) } & $\mathrm{C}$ group & $195.0 \pm 23.0$ & $118.8 \pm 32.7^{*}$ & $122.7 \pm 28.0 *$ \\
\hline & A group & $216.0 \pm 23.2$ & $193.0 \pm 32.5$ & $174.7 \pm 16.9$ \\
\hline
\end{tabular}

$R$ 10, 10 minutes reperfusion; $R$ 30, 30 minutes reperfusion.

${ }^{*} p<0.05$, compared with baseline value.

$\dagger p<0.05$, C group versus A group.

( $n=48$; six rat hearts were used at each time of each group. All hearts were also used at the measurement of cGMP)

Measurement of cGMP. Cyclic GMP was measured in the heart by a radioimmunoassay. Tissue samples were taken at the same times as for $\mathrm{Ca}$ measurements and immediately frozen in liquid nitrogen. The samples were homogenized in $0.1 \mathrm{ml}$ of a $0.1 \mathrm{~N} \mathrm{HCl}-10 \mathrm{mmol} / \mathrm{L}$ ethylenediaminetetraacetic acid solution and then immersed in boiling water for 3 minutes to provide an acid extract suitable for measurements of cGMP concentration. One hundred microliters of sample (either a cGMP standard or a test solution) was added to $100 \mu \mathrm{L}$ of a dioxane-triethylamine mixture containing succinic anhydride. After 10 minutes at room temperature, the reaction mixture was added to 0.5 to $1.0 \mathrm{ml}$ of $0.5 \mathrm{mmol} / \mathrm{L}$ imidazole buffer containing $0.5 \%$ bovine serum albumin, $8 \mathrm{mmol} / \mathrm{L}$ theophylline, and $0.001 \%$ streptomycin. The above mixture $(100 \mu \mathrm{l})$ was added to $100 \mu \mathrm{l}$ of $\left[{ }^{125}\right.$ I]SCAMPTME $(15,000$ to $20,000 \mathrm{cpm}$ in an amount less than $104 \mathrm{~mol}$ ) and $100 \mu \mathrm{l}$ of the diluted antisera. The mixture was kept at $4^{\circ} \mathrm{C}$ overnight (about 15 hours). A cold solution of dextran-coated charcoal $(0.5 \mathrm{ml})$ was added to the above mixture and cooled in an ice-cold water bath. The charcoal was then spun down, and $0.5 \mathrm{ml}$ of the supernatant was counted for radioactivity in a gamma spectrometer $(n=48)$.

Measurement of phosphatidylinositols. Separate hearts were processed to measure inositol-1,4,5-monophosphate content. After stabilization, they were perfused for 45 minutes with $50 \mathrm{ml} \mathrm{mKHB}$ buffer containing $20 \mu \mathrm{Ci}$ of $[3 \mathrm{H}]$ myo-inositol, and then perfused with mKHB buffer containing $10 \mathrm{mmol} / \mathrm{L} \mathrm{LiCl}$ to inhibit inositol phosphate phosphatase. They then were randomly assigned either the $\mathrm{C}$ group or A group. At the same times as for calcium measurements, the left ventricle was excised from the heart and rapidly frozen in liquid nitrogen. For measurement of $[3 \mathrm{H}]$ inositol triphosphate, the frozen tissue was homogenized with $5 \%$ perchloric acid with a Polytron homogenizer (Brinkmann Instruments, Inc., Westbury, N.Y.) and centrifuged at 8000 for 10 minutes. The supernatant was neutralized with $5 \mathrm{mmol} / \mathrm{L} \mathrm{K}_{2} \mathrm{CO}_{3}$, and the precipitate was removed by centrifugation at $1000 \mathrm{~g}$ for 5 minutes. The supernatant was applied to the anion exchange column. The $1 \mathrm{ml}$ fractions eluted from the column were counted in duplicate for radioactivity ${ }^{21}$ ( $n=48$; six hearts were used at each time in each group).

Statistical analysis. Results are expressed as mean \pm standard error of the mean for the number of observations. Data were analyzed by analysis of variance (ANOVA)-factorial for differences between the groups using Scheffe's test, and by ANOVA-repeated measurements for accounting for potential changes between the different points of time throughout the experimental protocol within the group by using Scheffe's test. ANOVA-repeated measurements were applied to each parameter for examining both entire measuring points (data from the preischemic baseline to the end of reperfusion) and points after reperfusion. Sequential changes in each parameter also were examined by paired $t$ test in each group. A level of $p<0.05$ was accepted as being statistically significant.

\section{Results}

Hemodynamics. No episodes of ventricular arrhythmia occurred after reperfusion in either group. Left ventricular functional data for the two groups at baseline before entering the group protocols and after 10 or 30 minutes of reperfusion are displayed in Table I.

In the group pretreated with L-arginine, $\mathrm{dp} \max$ and LV dp/dt max were significantly higher than in the control group after 10 and 30 minutes of reperfusion. No significant differences in heart rate were noted between the L-arginine-pretreated group and the control group.

In the $\mathrm{C}$ group but not the $\mathrm{A}$ group, coronary flow was significantly reduced at 30 minutes of reperfusion compared with the preischemic values.

Tissue cGMP content (Fig. 2). After 30 minutes of ischemia and reperfusion, cGMP content was significantly increased in the L-arginine-pretreated group (base: $1.06 \pm 0.12$, I30: $1.94 \pm 0.09$, R10: $1.88 \pm 0.14, \mathrm{R} 30: 1.55 \pm 0.10 \mathrm{pmol} / \mathrm{mg}$ protein $)$, compared with the $\mathrm{C}$ group (base: $1.04 \pm 0.14$, I30: 


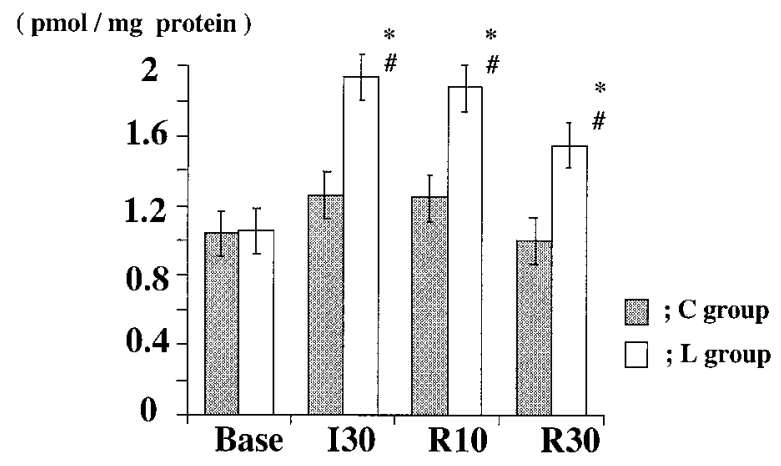

Fig. 2. Cyclic GMP content. cyclic GMP (cGMP) contents in the myocardium were measured by radioimmunoassay at baseline (Base), after 30 minutes of ischemia (I30), after 10 minutes reperfusion (R10), and after 30 minutes reperfusion (R30). In the L group, cGMP contents were significantly higher than the $\mathrm{C}$ group after ischemia and reperfusion. ${ }^{*} p=0.02, \mathrm{C}$ group versus $\mathrm{L}$ group; \#p = 0.01 compared with the values of baseline.

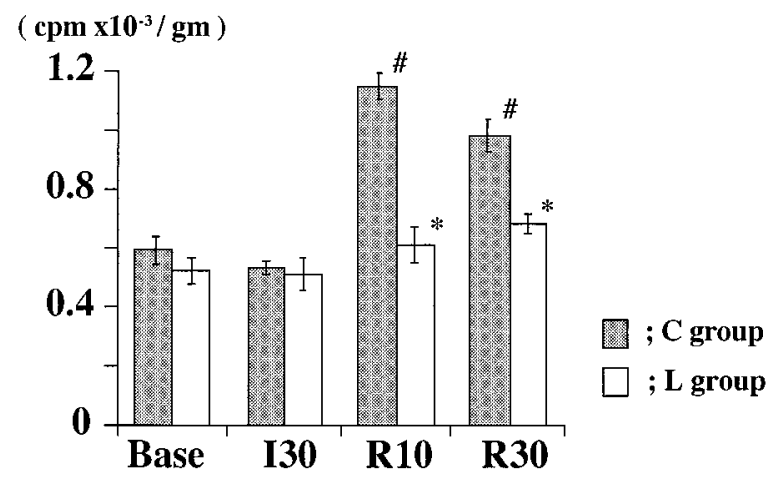

Fig. 3. The content of inositol-1,4,5-monophosphate $\left(\mathrm{IP}_{3}\right) . \mathrm{IP}_{3}$ significantly increased 10 minutes and 30 minutes after reperfusion in the $\mathrm{C}$ group. However, in the $\mathrm{L}$ group there was no differences between the value of baseline and after reperfusion. ${ }^{*} p=0.03, \mathrm{C}$ group versus L group; $\# p=0.01$, compared with the values of baseline.

$1.26 \pm 0.08, \mathrm{R} 10: 1.25 \pm 0.14, \mathrm{R} 30: 1.00 \pm 0.09$ $\mathrm{pmol} / \mathrm{mg}$ protein, $p=0.02$ ) at each time except for base. No change in cGMP content was evident in the control group during the experiment.

Inositol 1,4,5-triphosphate (IP3; Fig. 3). In the control group, IP3 was significantly increased after 10 and 30 minutes of reperfusion compared with baseline and after 30 minutes of ischemia (base: $0.59 \pm 0.045, \mathrm{I} 30 ; 0.53 \pm 0.023, \mathrm{R} 10: 1.15 \pm 0.045$, R30: $\left.0.98 \pm 0.056 \mathrm{cpm} \times 10^{-3} / \mathrm{gm}, p=0.01\right)$.

However, in the L-arginine-pretreated group, no differences were found between preischemic values

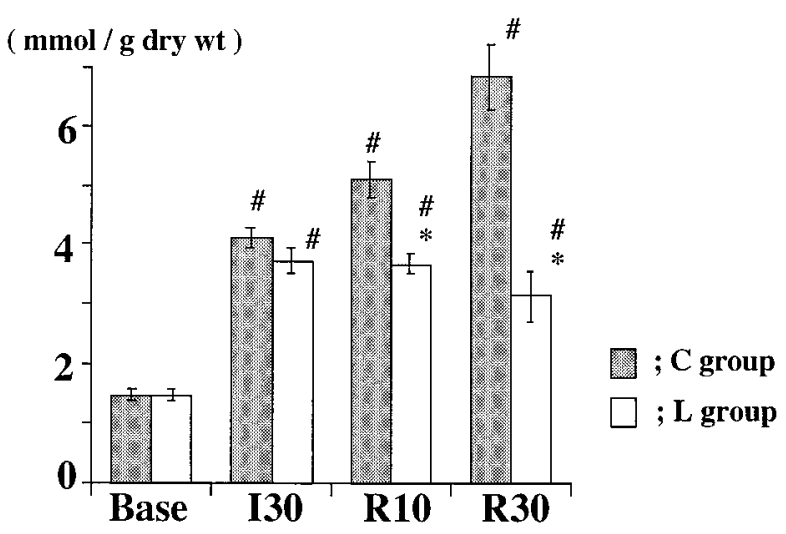

Fig. 4. Cytosolic $\mathrm{Ca}^{2+}$ content. Cytosolic $\mathrm{Ca}^{2+}$ content significantly increased after ischemia and reperfusion in both groups. However, in the $\mathrm{C}$ group, the absolute values were significantly higher in the $\mathrm{L}$ group after reperfusion. ${ }^{*} p=0.01, \mathrm{C}$ group versus L group; $\# p=0.02$, compared with the values of baseline.

and those after 30 minutes of ischemia, 10 minutes of reperfusion, and 30 minutes of reperfusion (base: $0.52 \pm 0.042$, I30; $0.51 \pm 0.054$, R10: $0.61 \pm 0.062$, R30: $0.68 \pm 0.032 \mathrm{cpm} \times 10^{-3} / \mathrm{gm}, p=0.02$ ), and the values of R10 and R30 in the A group were significantly lower than those in the $\mathrm{C}$ group, respectively $(p=0.03)$.

$\mathrm{Ca}^{2+}$ content (Fig. 4). In both groups, $\mathrm{Ca}^{2+}$ content was significantly increased after 30 minutes of ischemia compared with preischemic values, with no differences between two groups.

After reperfusion, however, $\mathrm{Ca}^{2+}$ content significantly increased in the control group (base: $1.46 \pm$ 0.109, I30; $4.12 \pm 0.164$, R10: $5.11 \pm 0.314$, R30: $6.86 \pm 0.544 \mathrm{mmol} / \mathrm{gm}$ dry weight, $p=0.02)$. In the L-arginine-pretreated group, no significant change in $\mathrm{Ca}^{2+}$ was noted after reperfusion (base: $1.46 \pm$ 0.109, I30: $3.72 \pm 0.214$, R10: $3.68 \pm 0.158, \mathrm{R} 30$ : $3.14 \pm 0.428 \mathrm{mmol} / \mathrm{gm}$ dry weight, $p=0.01$ ).

\section{Discussion}

Previous studies have suggested that NO protects against ischemia-reperfusion injury, and cardioprotective mechanisms may be due to coronary vasodilatation, inhibition of neutrophil adherence, inhibition of platelet aggregation, protection of coronary endothelial cell function, and neutralization of free radicals. Other studies, reporting detrimental effects of $\mathrm{NO}$ on hearts in reperfusion ${ }^{2,3,22}$ have suggested that NO inhibits mitochondrial function and produces peroxynitrite. Taken together, these results 
suggest that NO has opposing effects, both beneficial and detrimental, on myocardium and coronary endothelium in this situation.

Because NO has the detrimental effects of the ischemia-reperfusion myocardial injury, the concentration of L-arginine and the timing of L-arginine infusion have been difficult problems. In our experiment the infusion of higher than $3 \mathrm{mmol} / \mathrm{L} \mathrm{L}$ arginine caused the inhibition of cardiac function (result was not shown). Engelman and colleagues ${ }^{23}$ reported that the different timing of L-arginine infusion led the detrimental effects of cardioprotection. They reported that preischemic infusion of L-arginine reduced reperfusion injury, but L-arginine infusion during reperfusion did not lead to a cardioprotective effect. Matheis and colleagues ${ }^{22}$ reported that administration of the NO synthase inhibitor to the extracorporeal circuit afforded protection against myocardial reoxygenation injury. The extreme release of NO on the reperfusion or reoxygenation phase may stimulate some cytotoxic oxygen radical production and promotes the reperfusion injury.

Given the complexity of these results, we speculated that $\mathrm{NO}$ may have different effects on the myocardium in the ischemic phase and the reperfusion phase. ${ }^{23}$ In this study we investigated how preischemic increase of NO influences the cardioprotection on the reperfusion phase, especially regarding any association between $\mathrm{NO}$ and $\mathrm{Ca}^{2+}$ overload.

Although $\mathrm{Ca}^{2+}$ is important in cell metabolism as a second messenger, extreme accumulations in the cytosol cause cell injury. Such accumulation in hearts during ischemia-reperfusion is known as $\mathrm{Ca}^{2+}$ overload, which contributes to reperfusion injury, including myocardial stunning. $\mathrm{Ca}^{2+}$ overload is caused by failure of three regulatory systems of cytosolic $\mathrm{Ca}^{2+}$ content: the cell membrane, through which $\mathrm{Ca}^{2+}$ normally cannot pass; $\mathrm{Ca}^{2+}$ pumps and channels related to the membrane; and mechanisms sequestering intracellular $\mathrm{Ca}^{2+}$ stores. Previous investigators have found that inhibition of $\mathrm{Ca}^{2+}$ overload with various calcium channel blockers reduces reperfusion injury. The sarcoplasmic reticulum also is critical to regulation of intracellular $\mathrm{Ca}^{2+}$ stores $^{24}$ and release of calcium from the sarcoplasmic reticulum is mediated by IP3. In this study we observed that IP3 increased after 10 and 30 minutes of reperfusion compared with preischemic values, as did Ca. The relationship between IP3 and $\mathrm{Ca}$ in our results suggests that increased IP3 induced more $\mathrm{Ca}$ accumulation, resulting in reperfusion injury. ${ }^{25-28}$

We now consider the mechanism by which NO reduces IP3 after reperfusion. As an intracellular messenger, NO activates sGC, which causes an increase in cGMP concentration. The diverse biologic effects of cGMP include relaxation of vascular smooth muscle, inhibition of platelet aggregation, and regulation of phosphodiesterase and protein kinase. Clementi and coworkers ${ }^{29}$ reported that in neural cells NO appeared to modulate inositol phosphate generation and $\mathrm{Ca}^{2+}$ release primarily at the level of phospholipase C, mediated by cGMPdependent protein kinase I. Evans and colleagues ${ }^{30}$ have demonstrated that increasing the level of cGMP in the myocardium inhibited both positive inotropic and phosphatidylinositol responses to $\alpha_{1-}$ stimulation in isolated preparations of papillary muscle. Hirata and coworkers ${ }^{5}$ investigated the mechanism of cGMP inhibition of inositol phosphate formation in rat aorta, and Nakashima and coworkers ${ }^{6}$ reported cGMP inhibition of polyphosphoinositide hydrolysis in human platelets. Our data show that cGMP accumulation is significantly higher in the L-arginine-pretreatment group than in the control group after reperfusion, and it was thought that accumulated cGMP in the treated group inhibited the increase of IP3 and $\mathrm{Ca}^{2+}$ in the similar mechanism, followed by significantly better cardioprotection.

Previous studies have demonstrated cardioprotective mechanisms of NO caused by coronary vasodilatation. However, our results demonstrate other mechanisms. These data in our study indicate that the cardioprotective effect of L-arginine pretreatment may be due to the inhibition of calcium overload by means of cGMP.

Because NO has various effects including peroxynitrite production, further preclinical studies are necessary to refine dosage and timing of the NO precursor pretreatment protocol. $^{23}$

\section{REFERENCES}

1. Stadler J, Billiar TR, Curran RD, Stuehr DJ, Ochoa JB, Simmons RL. Effect of exogenous and endogenous nitric oxide on mitochondrial respiration of rat hepatochtes. Am J Physiol 1991;260:C910-6.

2. Takeuchi K, Takashima K, Suzuki S, Fukui K. Basic amino acid, L-arginine aggravates ischemia-reperfusion injury. J Jpn Thorac Surg 1996;44:155-61.

3. Stamler JS, Singel DJ, Loscalzo J. Biochemistry of nitric oxide and its redox-activated forms. Science 1992;258:1898902.

4. Gruetter CA, Gruetter DY, Lyon JE, Kadowitz PJ, Ignarro 
LJ. Relationship between cyclic guanosine $3^{\prime}: 5^{\prime}$-monophosphate formation and relaxation of coronary arterial smooth muscle by glyceryl trinitrate, nitroprusside, nitrite and nitric oxide: effects of methylene blue and methemoglobin. J Pharmacol Exp Ther 1981;219:181-6.

5. Hirata M, Kohse KP, Chang CH, Ikebe T, Murad F. Mechanism of cyclic GMP inhibition of inositol phosphate formation in rat segments and cultured bovine aortic smooth muscle cells. J Biol Chem 1990;265:1268-73.

6. Nakashima S, Tohmatsu T, Hattori H, Okano Y, Nozawa Y. Inhibitory action of cyclic GMP on secretion, polyphosphoinositide hydrolysis and calcium mobilization in thrombinstimulated human platelets. Biochem Biophys Res Comm 1986;135:1099-104.

7. Karaki H, Sato K, Ozaki H, Murakami K. Effects of sodium nitroprusside on cytosolic calcium level in vascular smooth muscle. Eur J Pharmacol 1988;156:259-66.

8. Andriantsitohaina R, Lagaud JL, Andre A, Muller B, Stoclet JC. Effects of cGMP on calcium handling in ATP-stimulated rat resistance arteries. Am J Physiol 1995;268:H1223-31.

9. Yoshida Y, Sun HT, Cai JQ, S I. Cyclic GMP-dependent protein kinase stimulates the plasma membrane $\mathrm{Ca}^{2+}$ pump ATPase of vascular smooth muscle via phosphorylation of a 240-kDa protein. J Biol Chem 1986;266:19819-25.

10. Sato H, Zhao ZQ, McGee DS, Williams MW, Hammon JW, Vinten-Johansen J. Supplemental L-arginine during cardioplegic arrest and reperfusion avoids regional postischemic injury. J Thorac Cardiovasc Surg 1995;110:302-14.

11. Weyrich AS, Ma X, Sakamoto T. The role of L-arginine in ameliorating reperfusion injury after myocardial ischemia in the cat. Circulation 1992;86:279-88.

12. Lefer AM. Attenuation of myocardial ischemia-reperfusion injury with nitric oxide replacement therapy. Ann Thorac Surg 1995;60:847-51.

13. Kubes P, Suzuki M, Granger DN. Nitric oxide: an endogenous modulator of leukocyte adhesion. Proc Natl Acad Sci U S A 1991;88:4651-5.

14. Mullane K, Engler R. Proclivitiy of activated neutrophils to cause postischemic cardiac dysfunction: participation in stunning? Cardiovasc Drugs Ther 1991;5:915-24.

15. Kawata H, Sawatari K, Mayer Jr JE. Evidence for the role of neutrophils in reperfusion injury after cold cardioplegic ischemia in neonatal lambs. J Thorac Cardiovasc Surg 1992; 103:908-18.

16. Lefer DJ, Nakanishi K, Vinten-Johansen J. Endothelial and myocardial cell protection by a cystein-containing nitric oxide donor after myocardial ischemia and reperfusion. J Cardiovasc Pharmacol 1993;22(Suppl 7):S34-43.
17. Beckman JS, Beckman TW, Chen J, Marshall PA. Apparent hydroxyl radical production by peroxynitrite: implications for endothelial injury from nitric oxide and superoxide. Proc Natl Acad Sci U S A 1990;87:1620-4.

18. Clancy RM, Leszczynska-Piziak J, Abramson SB. Nitric oxide, an endothelial cell relaxation factor, inhibits neutrophil superoxide anion production via a direct action on the NADPH oxidase. J Clin Invest 1992;90:1116-21.

19. Bolli R, Jeroudi MO, Patel BS, et al. Marked reduction of free radical generation and contractile dysfunction by antioxidant therapy begun at the time of reperfusion. Circ Res 1989;65:607-22.

20. Nakanishi K, Vinten-Johansen J, Lefer DJ, et al. Intracoronary L-arginine during reperfusion improves endothelial function and reduces infarct size. Am J Physiol 1992;263: H1650-8.

21. Maulik N, Engelman DT, Watanabe M, et al. Nitric oxide signaling in ischemic heart. Cardiovasc Res 1995;30:593-601.

22. Matheis G, Sherman MP, Buckberg GD, Haybron DM, Young HH, Ignarro LJ. Role of L-arginine-nitric oxide pathway in myocardial reoxygenation injury. Am J Physiol 1992;262:H616-20.

23. Engelman DT, Watanabe M, Maulik N, et al. Critical timing of nitric oxide supplementation in cardioplegic arrest and reperfusion. Circulation 1996;94(Suppl):II407-11.

24. Berridge MJ. Inositol triphosphate and calcium signaling. Nature 1993;361:315-25.

25. Anderson KE, Dart AM, Woodcock EA. Inositol phosphate release and metabolism during myocardial ischemia and reperfusion in rat heart. Circ Res 1995;76:261-8.

26. Mouton R, Genade S, Huisamen B, Malan M, Lochner A. The effect of ischemia-reperfusion on $[3 \mathrm{H}]$ inositol phosphates and Ins $(1,4,5) \mathrm{P} 3$ levels in cardiac atria and ventricles: a comparative study. Mol Cell Biochem 1992;115:195-202.

27. Woodcock EA, White LBS, Smith AI, McLeod JK. Stimulation of phosphatidylinositol metabolism in the isolated, perfused rat heart. Circ Res 1987;61:625-31.

28. Otani H, Prasad MR, Engelman RM, Otani H, Cordis GA, Das DK. Enhanced phosphodiesteratic breakdown and turnover of phosphoinositides during reperfusion of ischemic rat heart. Circ Res 1988;63:930-6.

29. Clementi E, Vecchio I, Sciorati CGN. Nitric oxide modulation of agonist-evoked intracellular $\mathrm{Ca}^{2+}$ release in neurosecretory PC-12 cells: inhibition of phospholipase $\mathrm{C}$ activity via cyclic GMP-dependent protein kinase I. Mol Pharmacol 1995; 47:517-24.

30. Evans HG, Shah AM, Sakamoto T. Cyclic GMP inhibits the inotropic response to alpha 1-adrenoceptors in the papillary muscle of the ferret. Cardioscience 1992;3:257-64. 